\title{
COVID-19 y su incidencia en el empleo en México
}

COVID-19 and its impact on employment in Mexico

COVID-19 e sua incidência no emprego no México

\author{
José Manuel Osorio Atondo \\ jose.osorio@ues.mx \\ Universidad Estatal de Sonora - México \\ https://orcid.org/0000-0001-8508-9953 \\ Luz Alicia Osorio Atondo \\ luz.osorio@ues.mx \\ Universidad Estatal de Sonora - México \\ https://orcid.org/0000-0002-4101-333X
}

\begin{abstract}
RESUMEN
La crisis sanitaria inducida por el COVID-19, ha puesto a prueba a todos los gobiernos y sociedades de todo el mundo al provocar una crisis económica global de magnitudes antes no registrada, frenándose la economía, con afectaciones en las empresas y con ello, la pérdida de empleos y percepciones económicas de los trabajadores. Por tal motivo, con el apoyo en los datos emitidos por el Instituto Nacional de Estadística y Geografía (INEGI) y mediante sus instrumentos de Encuesta Nacional de Ocupación y Empleo (ENOE), Encuesta sobre el Impacto Económico Generado por COVID-19 en las Empresas (ECOVID-IE) y la Encuesta Telefónica sobre COVID-19 y Mercado Laboral (ECOVID-ML), así como en las cifras proporcionadas en los datos abiertos del Instituto Mexicano del Seguro Social (IMSS); se exhibe su incidencia en el empleo en México, mostrándose una recuperación sustancial de la ocupación laboral en el país al culminar el confinamiento. No obstante, se requiere de la implementación de políticas públicas orientadas a mitigar el menoscabo económico provocado por dicha enfermedad y que ha perjudicado a las familias mexicanas.
\end{abstract}

Palabras clave: COVID-19, coronavirus, pandemia, empleo, desempleo, mercado laboral.

\begin{abstract}
The health crisis associated with COVID-19 has put governments and societies around the world to the test, unprecedented causing economic slowdown, unemployment, and concomitant loss of income among the working class. Relying on data released by the National Institute of Statistics and Geography's (INEGI) National Survey of Occupation and Employment (ENOE), the Economic Impact of COVID-19 on Companies Survey (ECOVID-IE) and its COVID-19 and Labor Market Telephone Survey (ECOVID-ML), in conjunction with public data from the Mexican Institute of Social Security (IMSS), a picture of the impact of COVID-19 on employment in Mexico becomes clear, evidencing substantial recovery of labor occupation in the country once confinement measures were relaxed. Nonetheless, it is necessary to implement public policies aimed at mitigating the economic damage done to Mexican families because of the pandemic.
\end{abstract}

Keywords: COVID-19, coronavirus, pandemic, employment, unemployment, labor market.

\section{RESUMO}


A crise de saúde induzida pela COVID-19 colocou todos os governos do mundo à prova, ocasionando uma crise econômica global de magnitude nunca antes registrada, atingindo a economia, afetando as empresas e com isso, a perda de empregos e das percepções econômicas dos trabalhadores. Por esta razão, com o apoio dos dados emitidos pelo Instituto Nacional de Estatística e Geografia (INEGI) e através de sua Pesquisa Nacional de Ocupação e Emprego (ENOE), A Pesquisa sobre o Impacto Econômico Gerado pela COVID-19 nas Empresas (ECOVID-IE) e a Pesquisa Telefônica sobre COVID-19 e Mercado de Trabalho (ECOVID-ML), assim como os números fornecidos nos dados abertos do Instituto Mexicano de Seguridade Social (IMSS); o impacto da COVID no emprego no México é mostrado com uma recuperação substancial do emprego no país após o fim do confinamento. Entretanto, a implementação de políticas públicas destinadas a mitigar os danos econômico provocado por esta doença, que tem sido prejudicial para as famílias mexicanas, é urgente.

Palavras chave: COVID-19, coronavírus, pandemia, emprego, desemprego, mercado de trabalho.

\section{INTRODUCCIÓN}

La Organización Mundial de la Salud (OMS) notificó el 31 de diciembre del 2019, la confirmación del primer caso de Covid19 en la provincia de Wuhan, China, presentado el día 8 del mismo período (Libertad y Desarrollo, 2020:1); enfermedad catalogada inicialmente como neumonía, denominada a la postre como Síndrome Respiratorio Agudo Severo Coronavirus 2 (SARS-CoV-2) y clasificándose finalmente como pandemia por el mismo órgano de salud (Ramírez et al, 2020:1).

En consecuencia, a un año y medio se ha expuesto en todo el mundo una de las peores crisis sanitaria causada por la pandemia del coronavirus, incitando el aislamiento de las sociedades, el cierre de fronteras, la interrupción de las economías con gran afectación negativa a corto, mediano y largo plazo; con acentuación de aumento del desempleo, la disminución de los ingresos salariales, la ampliación de la pobreza, desinversión privada, cadenas de valor menos integradas, bajo crecimiento económico y, por ello, el menoscabo de las capacidades productivas y de la fuerza de trabajo (CEPAL,2020:2).

Por si fuera poco, en atención a los datos emitidos en tiempo real por la Johns Hopkins School y publicados por el Instituto Mexicano del Seguro Social (IMSS), a la fecha se registran cerca de doscientos cuatro millones de contagios y más de cuatro millones trecientas mil lamentables defunciones en el ámbito global; siendo Estados Unidos de América, India, Brasil, Rusia y Francia los cinco países más afectados con casos de contagio; mientras que, en el caso de fallecimientos se encuentran Estados Unidos, Brasil, India, México, Perú y Rusia.

Precisamente para el caso que nos atañe, México sigue siendo uno de los países más afectados por la pandemia, en virtud que, en atención a los datos emitidos por el Gobierno federal contabiliza a la fecha más de dos millones novecientos mil casos de contagio confirmados y por encima de doscientos cincuenta y ocho mil defunciones por Covid-19 (covid-19 Tablero México), escenario que aún sigue siendo adverso al enfrentarse la sociedad mexicana con la nueva variante Delta, con afectaciones graves en la salud y por ende en la economía del país.

En los marcos de las observaciones anteriores, a través del presente estudio se expone el contexto de los efectos del Covid-19 en el empleo en México, soportándose el análisis con los datos emitidos por el Instituto Nacional de Estadística y Geografía (INEGI), mediante sus instrumentos de Encuesta Nacional de Ocupación y Empleo (ENOE), Encuesta sobre el Impacto Económico Generado por COVID-19 en las Empresas (ECOVID-IE) y la Encuesta Telefónica sobre COVID-19 
y Mercado Laboral (ECOVID-ML), así como en las cifras disponibles en los datos abiertos del Instituto Mexicano del Seguro Social (IMSS).

\section{FUNDAMENTACIÓN TEÓRICA}

Entre las acciones más relevantes para afrontar el Covid-19 ha sido el intentar de impedir la propagación del virus a través del confinamiento con período de cuarentena y el distanciamiento social, obteniéndose en la mayoría de los países efectos positivos para la salud y disminución de la curva de contagios. Sin embargo, tales medidas afectaron las actividades económicas al contraerse la producción o incluso la paralización total de los distintos sectores, incidiendo con ello en el empleo, las horas de trabajo y por ende en los salarios de los trabajadores, especialmente en el año 2020.

De tal manera que en atención a las más recientes evaluaciones económicas, se exhibe la gran afectación de los mercados de trabajo a nivel mundial durante el año 2020 sin precedente histórico; toda vez que se perdió el 8.8 por ciento de las horas de trabajo globales con respecto al cuarto trimestre del 2019, lo que corresponde a 255 millones de empleos de tiempo completo y siendo cuatro veces superior a la crisis financiera mundial del 2019; escenario adverso principalmente en América Latina y el Caribe, Europa meridional y Asia meridional (OIT, 2021).

Derivado de la propagación del coronavirus, muchos de los países de América Latina establecieron una serie de acciones en búsqueda de frenarlo, destacando las medidas de confinamiento, limitaciones a la movilidad social y la interrupción total o parcial a la actividad económica (Acevedo et al., 202:2). Precisamente en esta misma postura, con base en las recomendaciones formuladas por la Organización Mundial de la Salud (OMS), el Gobierno de México instruyó una serie de acciones y medidas provisorias para neutralizar y atenuar el virus también referido como SARS-CoV2; destacando el incremento de las capacidades de vigilancia epidemial y análisis de laboratorio para el sondeo de casos posibles, la implementación de acciones cautelares de viajeros extranjeros, la preparación a especialistas de la salud, la notificación de riesgos a la sociedad, la reciprocidad sistemática y transparente con organizaciones internacionales, entre otras; todo esto con base en la información expresada por la Secretaría de Salud (SS).

Ante tal escenario, el 24 de marzo del 2020 se instituyeron algunas medidas y sugerencias provisorias para los sectores público, privado y social; resaltando, la abstención de la asistencia al trabajo de los adultos mayores de 65 años, la interrupción de actividades de tales sectores y que involucraran la concentración de personal, así como la no suspensión de las operaciones de organizaciones o empresas indispensables para contrarrestar tal eventualidad, precisándose el mantenimiento de las relaciones laborales en atención a los contratos individuales y colectivos con sustento en la Ley Federal del Trabajo (LFT) y el artículo 123 de la Constitución Política de los Estados Unidos Mexicanos (CPEUM) (DOF, 24 de marzo del 2020).

Posteriormente, el 27 de marzo se emitió un decreto de medidas extraordinarias, estableciéndose la imperiosa necesidad de la coordinación de dependencias y entidades de la Administración Pública Federal (APF) para la instauración de medidas de mitigación control Covid-19 en las zonas afectadas de todo el territorio nacional (DOF, 27 del marzo 2020); informándose inmediatamente el 30 de marzo mediante un acuerdo la declaración como emergencia sanitaria causada por la misma epidemia, dictándose diversas medidas por el Gobierno federal con el objeto de salvaguardar la salud de la sociedad (DOF, 30 de marzo del 2020).

Posteriormente, se implantaron medidas extraordinarias para los distintos sectores mediante el acuerdo publicado el 31 de marzo; sobresaliendo la orden inminente de la suspensión de las actividades no esenciales durante el lapso del 30 de marzo al 30 de abril del 2020, con el propósito de atenuar la propagación e impedir la carga de la enfermedad y muerte causada por el virus en la 
comunidad, prevaleciendo el ejercicio de las actividades necesarias para atender la emergencia; tales como la rama médica, paramédica, administrativa y de soporte al Sistema de Salud. Asimismo, el desarrollo de actividades económicas consideradas fundamentales de los sectores esenciales de la economía, financieras, enajenación de energéticos, recaudación tributaria, generación y distribución de agua potable, industria de alimentos y bebidas no etílicas, mercado de alimentos, entre otros (DOF, 31 de marzo del 2020).

A la postre, mediante el acuerdo publicado el 21 de abril se modificó la fracción I del artículo primero del acuerdo que antecedió, ampliándose el plazo de interrupción de las actividades económicas consideradas no fundamentales al 31 de mayo, con el mismo propósito de la mitigación de la propagación del virus (DOF, 12 de abril del 2021); contexto que incidió en las relaciones laborales individuales y colectivas de varios sectores económicos del país al cerrar sus puertas o bien interrumpir sus procesos productivos y/o prestación de servicios.

Dadas las condiciones que anteceden, en México se han realizado una serie de análisis sobre los efectos en el empleo, la distribución del ingreso y la pobreza, entre otros rubros; durante y posterior al confinamiento ocasionado por el Covid-19, estudios que se han soportado en distintas bases de datos e instrumentos disponibles y emitidos por instituciones gubernamentales u organismos nacionales. Verbigracia, Salas et al. (2020), exhiben que la suspensión de las actividades derivado de la emergencia sanitaria, ha provocado el incremento de la pobreza, así como la desigualdad; apoyándose dicho análisis en el índice de Gini.

En esta misma tesitura, Huesca, et al. (2021a), comparten en su investigación que la pandemia ocasionada por el coronavirus en México conllevará un menoscabo en los indicadores de bienestar, incluyendo un incremento importante en la pobreza extrema y la desigualdad, frenándose con ello el desarrollo social obtenido durante la administración gubernamental actual con un incremento en 3.5 puntos del índice de Gini, al situarse en 0.52. Para profundizar las incidencias de la pandemia, tal estudio se soportó en MEXMOD, modelo de microsimulación de impuestos y transferencias en México (Huesca y Llamas, 2020). Tal estudio consistió en valorar el efecto de las pérdidas del empleo e ingresos, sobre la pobreza y la distribución del ingreso, particularmente en el mes de mayo 2020, mes en el cual se perturbó principalmente la economía por la pandemia.

Asimismo, Huesca, et al. (2021b), mediante el empleo de un modelo probit para identificar a las personas en riesgo de perder el empleo con base en la Encuesta Nacional de Ingresos y Gastos en los Hogares 2018 (ENIGH) y las variantes en el empleo y los ingresos observados entre diciembre 2019 y mayo de 2020 con base en las encuestas de ENOE y ETOE, respectivamente, así como a través del uso de MEXMOD; se expone una pérdida de 12.1 millones de puestos de trabajo, escenario que muestra que la pobreza llega al $60.16 \%$, la pobreza extrema al $29.73 \%$ y la desigualdad creció en un $8.2 \%$.

De igual manera, Samaniego (2020), con base en los datos proporcionados por el IMSS, exterioriza el desplome del empleo en México, estimado en su momento de 5.0\% del trabajo formalizado entre fines de febrero y mayo del 2020, superando lo ya observado en el punto más crítico de la llamada recesión de 2008-2009 y en correlación a la crisis financiera de 1944-1996, la cual había sido la más profunda de los últimos 50 años. Mientras que Cota (2020), examinó la estimación de los efectos económicos de la pandemia y sus repercusiones iniciales en el mercado laboral en México, destacando el desplome de la población económicamente activa ocupada a partir del mes de abril y los trabajadores que se encontraban en la formalidad; utilizando además, un modelo de vectores autoregresivos para el pronósticos de las tendencias de la ocupación en el corto plazo, detectándose la advertencia del estancamiento en los niveles de ocupación de la Población Económicamente Activa (PEA) con posible recuperación en el primer trimestre del 2021. 
En otro de los análisis se expone que las acciones sanitarias retrasadas e implementadas por Estados Unidos de América en contra de la pandemia, provocaron una insondable recesión económica que incidió en el incremento inédito del desempleo; escenario en el cual las medidas adoptadas en México fueron insuficientes, profundizando la recesión que ya existía desde 2019. En tal contexto, las organizaciones han tenido que recurrir a las nuevas tecnologías digitales para promover la modalidad del trabajo a domicilio. De tal manera que, al apoyarse el análisis en la ENOE y metodologías de cadenas de Markov, se construyen posibles escenarios de movimiento laboral entre sectores en ocupación digital y no digital, exponiéndose que ante la presencia del Covid-19 la proporción del empleo digital será del $49 \%$ y la tasa del desempleo del $6 \%$ para el año 2021 (Huesca, et al., 2020).

\section{PROCEDIMENTOS METODOLÓGICOS}

En el proceso del estudio, se soportó en una metodología mixta exploratoria a través del análisis de tipo documental, descriptivo y cuantitativo; con el apoyo del examen de documentos de estudios empíricos sobro el tema de análisis; así como, la localización, fijación y tratamiento de datos emitidos por el INEGI con sus resultados exteriorizados en los instrumentos denominados en sus acrónimos como ENOE, ECOVID-IE, ECOVID-ML y las cifras emitidas en sus datos abiertos del IMSS; exhibiéndose el análisis mediante la estadística descriptiva con el apoyo de la herramienta de Excel, al exponerse el comportamiento de los datos proporcionados por dichos instrumentos.

Actualmente la ENOE es la encuesta más grande que se aplica en México de forma continua en los hogares, empleándose a partir de enero 2005 al sustituir al modelo de captación y procesamiento de la Encuesta Nacional de Empleo Urbano (ENUE) y de la Encuesta Nacional de Empleo (ENE). Entre sus objetivos generales resaltan el de asegurar que la nación disponga con datos estadísticos con representación federal, estatal y de las principales ciudades sobre características ocupacionales de la población; así como, el amplificar la oferta de indicadores estratégicos para el discernimiento íntegro de la realidad nacional y que sirva de soporte en la formulación de políticas laborales (INEGI, 2020a).

Para el desarrollo del estudio, se utilizaron de la ENOE los tabulados predefinidos básicos, mismos que exponen entre otros rubros, el comportamiento de la variable PEA, seleccionando para ello las cifras expuestas del primer trimestre del 2020 al primer trimestre del 2021. Rodríguez (2013), define a la PEA como el "segmento de la población en condiciones de trabajar y que desea hacerlo; por lo tanto puede estar ocupada (en sentido pleno o subempleada) y desocupada", es decir, en términos del mercado laboral, una persona corresponde a la PEA si forma parte de los proveedores $\mathrm{u}$ oferentes de servicios laborales que se encuentran ocupados al desempeñar una actividad económica, mientras que otros, se encuentran desocupados ejerciendo una presión mediante la búsqueda de trabajo (INEGI, 2020b).

En el contexto de la pandemia surgió el instrumento ECOVID-IE, con el objeto de obtener indicadores sobre las afectaciones de la contingencia causada por el Covid-19 en las empresas del país que desarrollan actividades económicas esenciales y no esenciales exclusivamente del sector industrial, comercio y servicios; excluyéndose en tal instrumento las del sector primario como la agricultura, ganadería, pesca, acuicultura y el sector gobierno. El marco de muestreo de tal herramienta, se conformó por 1,873,564 empresas clasificadas por su tamaño en grandes, Pequeñas y Medianas Empresas (PyMES) y Micro de acuerdo a su estratificación con la variable del personal ocupado (INEGI, 2020c). 
Tabla 1. Marco de muestreo ECOVID-IE.

\begin{tabular}{|c|c|c|c|}
\hline \multicolumn{3}{|c|}{ Esenciales } & \multirow{3}{*}{ Total } \\
\hline \multicolumn{3}{|c|}{ Tamaño de empresa } & \\
\hline Grandes & PyMES & Micros & \\
\hline 3,882 & 42,772 & 879,848 & 926,502 \\
\hline \multicolumn{3}{|c|}{ No esenciales } & \multirow{3}{*}{ Total } \\
\hline \multicolumn{3}{|c|}{ Tamaño de empresa } & \\
\hline Grandes & Pymes & Micros & \\
\hline 13,011 & 85,489 & 848,562 & 947,062 \\
\hline \multicolumn{3}{|c|}{ Total de Empresas } & $1,873,564$ \\
\hline
\end{tabular}

Fuente: ECOVID-IE 2020

De igual forma, para efectos del desarrollo del análisis, del instrumento ECOVID-IE se tomaron las bases de datos expresados en sus tabulados predefinidos básicos por tamaño de empresas de sus tres momentos de aplicación en los períodos de abril 2020, agosto 2020 y marzo del 2021. De entre su gran gama de variables, para el caso de estudio se seleccionaron las variables de: 1) número y clasificación de empresas que implementaron paros técnicos o cierres temporales ante la contingencia, 2) número y clasificación de empresas según sus días naturales que estuvo vigente el paro técnico o cierre temporal de la empresa durante la contingencia, 3) número y clasificación de empresas que tuvieron que efectuar la reducción de personal y, 4) número y clasificación de empresas que asumieron la reducción de remuneraciones y/o prestaciones al personal.

Asimismo, en el escenario de la contingencia sanitaria ocasionada por el Covid-19, se implementó la aplicación de ECOVID-ML, instrumento que tiene como objetivo proporcionar información complementaria para dar seguimiento del impacto de la pandemia en la ocupación y empleo, para el estudio del mercado laboral y el seguimiento de las políticas laborales; apoyándose en el muestreo de números telefónicos elegidos de forma aleatoria del Plan Nacional de Numeración del Instituto Federal de Telecomunicaciones (IFT) (INEGI, 2020b).

Del mismo modo, del instrumento ECOVID-ML se descargaron bases de datos expresados en sus tabulados predefinidos básicos por los períodos abril, mayo, junio y julio 2020; para efectos del estudio seleccionando entre sus rubros: 1) los motivos de ausencia temporal o suspensión laboral y 2) las razones por las que no trabajó las horas habituales.

Finalmente, con el apoyo de los datos abiertos emitidos por el IMSS, se seleccionó de su base de cifras, el comportamiento de la variable de los puestos de trabajo formales en México ante dicho instituto de seguridad social, es decir, el número de trabajadores inscritos antes, durante y posterior al confinamiento.

\section{RESULTADOS Y DISCUSIÓN.}

En atención a la información hasta el primer trimestre de 2020 proviene de la ENOE, en el segundo trimestre de 2020 corresponde a la Encuesta Telefónica de Ocupación y Empleo (ETOE) y a partir del tercer trimestre de 2020 la información se genera con la Encuesta Nacional de Ocupación y Empleo (Nueva edición) (ENOE-N), cifras emitidas por tales instrumentos y que exhiben el comportamiento de la PEA, limitándose el estudio de dicho instrumento del primer trimestre 2020 al primer trimestre del 2021, exponiéndose en tal caso la disminución en la PEA por encima de 10.2 millones, comparándose en los períodos de primer y segundo trimestre del 2020, lo que representa cerca del $19 \%$ de tal indicador. 
Asimismo, en los datos vertidos en dichos instrumentos se muestra el incremento del $15.36 \%$ de la PEA en situación como desocupada en los mismos períodos analizados, representados por más de 300 mil casos expuestos. De igual manera, a pesar de mostrarse una recuperación del indicador en análisis en los períodos trimestrales expuestos, es de apreciarse que posteriormente al confinamiento por la suspensión de actividades no esenciales y que se culminara en el mes de mayo del 2020, al cierre del primer trimestre del 2021 y en comparación al primer trimestre del 2020, se visualiza una reducción de 2.3 millones de la PEA, lo que simboliza el $4.2 \%$ menos en dicho período, reflejándose en tal contexto la no recuperación al inicios del 2021.

Gráfica 1. Comportamiento de la PEA.

Primer trimestre 2020 al primer trimestre 2021.

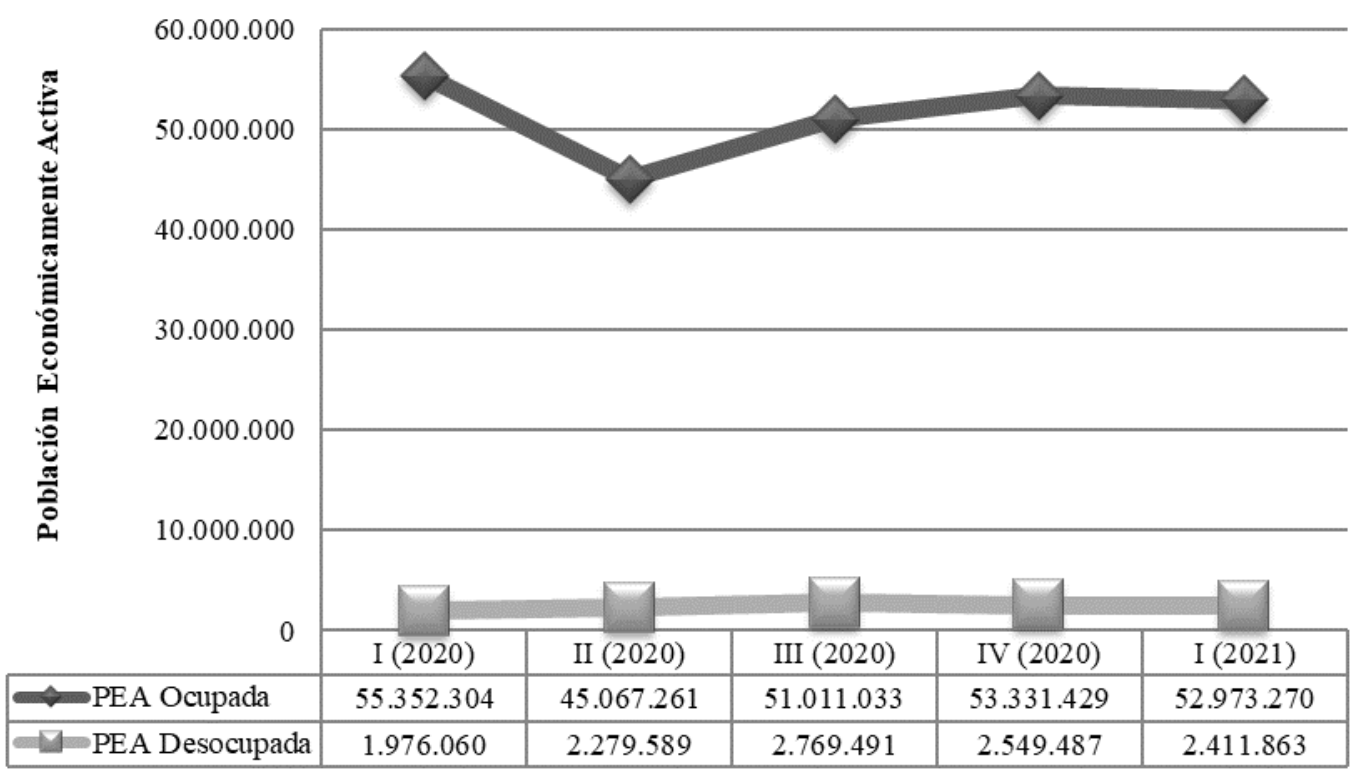

Fuente: Elaboración propia con datos emitidos en la ENOE 2021.

En esta misma postura, la pandemia ocasionó una distorsión económica y laboral en las organizaciones empresariales, tanto grandes como micro, pequeñas y medianas empresas, donde algunas de ellas tuvieron que efectuar la suspensión de sus actividades productivas o de prestación de servicios, coadyuvando con ello a la afectación en las relaciones laborales colectivas e individuales de trabajo. De tal manera que, en correspondencia al instrumento de ECOVID-IE en sus versiones de primera, segunda y tercera ronda, aplicadas en los meses de abril 2020, agosto 2020 y marzo del 2021, exponen entre sus variables el número de empresas que efectuaron paros técnicos o cierres temporales ante la contingencia originada por Covid-19, que durante la segunda y tercera ronda se presentaron los escenarios más adversos principalmente para las grandes, pequeñas y medianas empresas al tener que implementar dichas decisiones laborales, al representar en la mayoría de los casos por más del $90 \%$ de las entidades económicas en tal contexto. Es preciso señalar, que la variable del instrumento antes mencionado, no indica si el paro técnico o cierre temporal obedece a lo instituido en la LFT e identificado como suspensión de la relación laboral por contingencia sanitaria (Osorio, 2021). 
Gráfica 2.Porcentaje de empresas con implementación de paros técnicos o cierres temporales ante la contingencia originada por COVID-19.

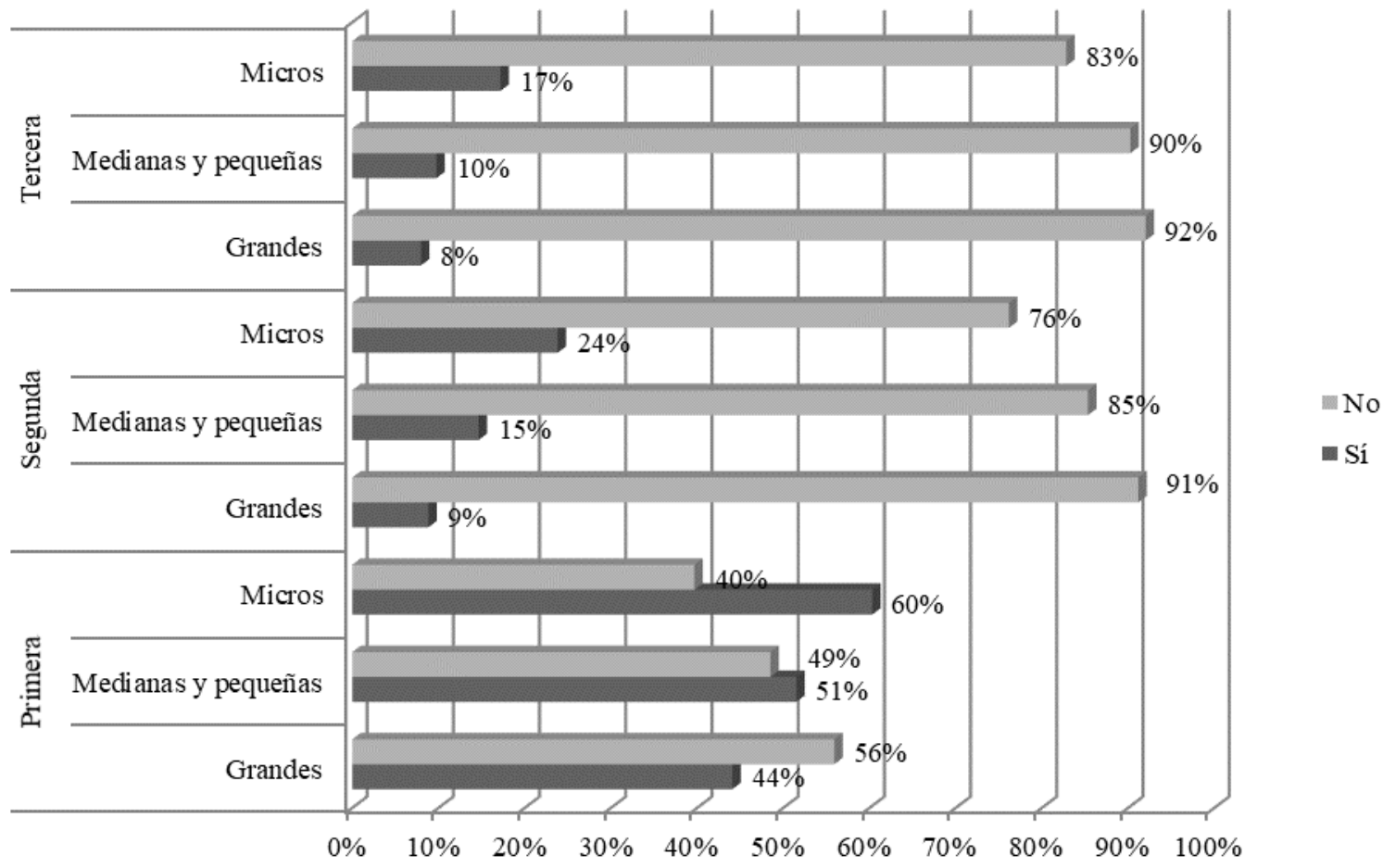

Fuente: Elaboración propia con datos emitidos en la ECOVID-IE 2021.

En este mismo sentido y con los datos emitidos de tal instrumento del INEGI, se expone que las grandes empresas en la primera, segunda y tercera ronda de aplicación de la encuesta, manifestaron el mayor número de días de suspensión temporal o paro técnico, es decir de 21 o más días que interrumpieron sus laborales; seguida por el caso de las pequeñas y medianas empresas. Con el comportamiento porcentual de los datos, se exhibe que la situación más compleja para las empresas fue durante el período de confinamiento, es decir en los meses de marzo a mayo del 2020. 
Gráfica 3.Porcentaje de días naturales que estuvo vigente el paro técnico o cierre temporal de la empresa durante la contingencia originada por COVID-19.

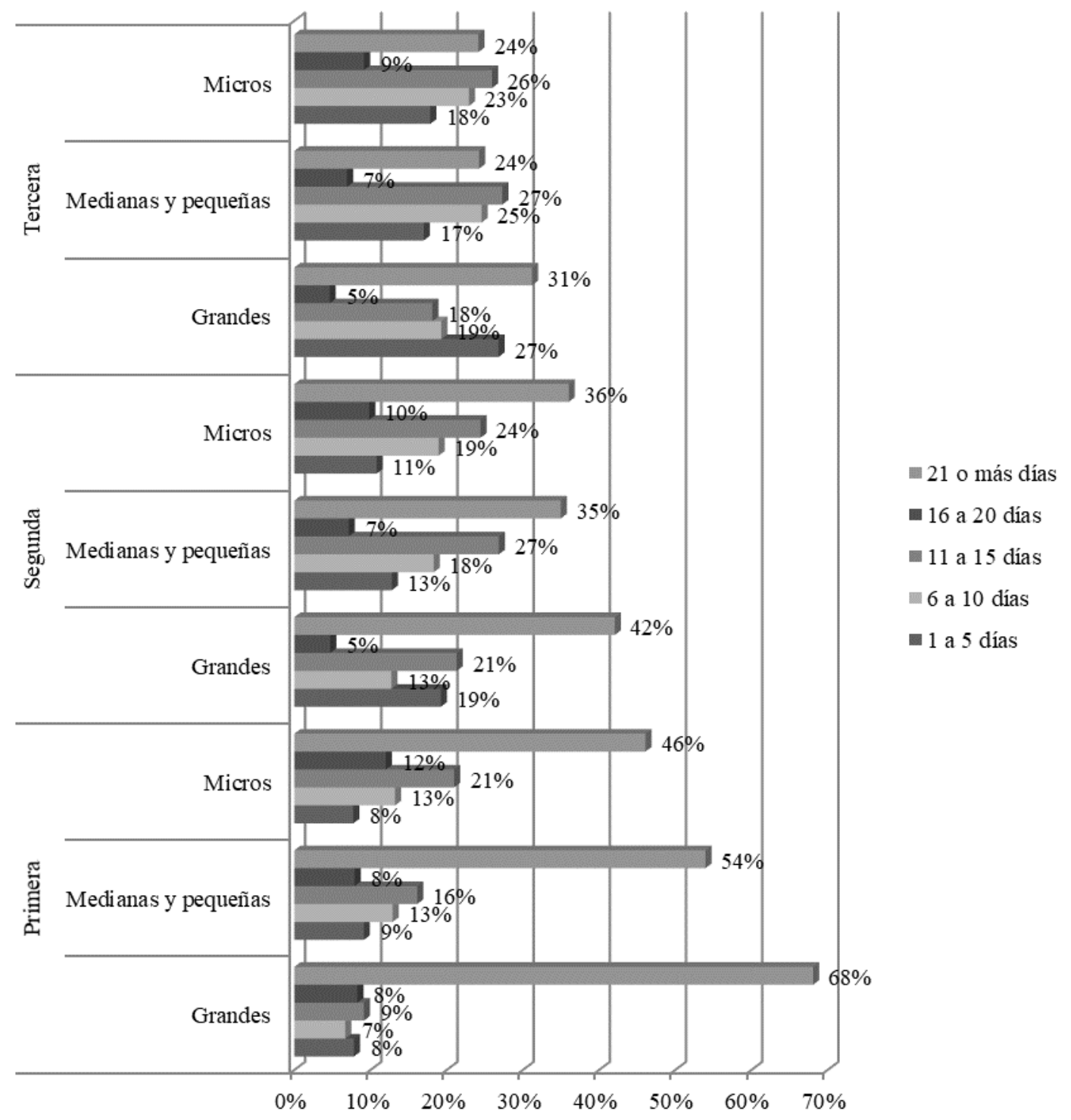

Fuente: Elaboración propia con datos emitidos en la ECOVID-IE 2021.

En esta misma tesitura, a través del mismo instrumento, se ostenta la afectación ocasionada por el coronavirus a la micro, pequeña y mediana empresa al tener que tomar la difícil decisión de disminuir el personal a su cargo; y por si fuera poco, implementar la reducción de las remuneraciones y/o prestaciones otorgadas a sus trabajadores, contexto que indudablemente incidió en los ingresos de los hogares del país. Tales datos muestran escenarios porcentuales por encima del $50 \%$ en las tres rondas de aplicación de la ECOVID-IE. 
Gráfica 4.Porcentaje de empresas que redujeron personal.

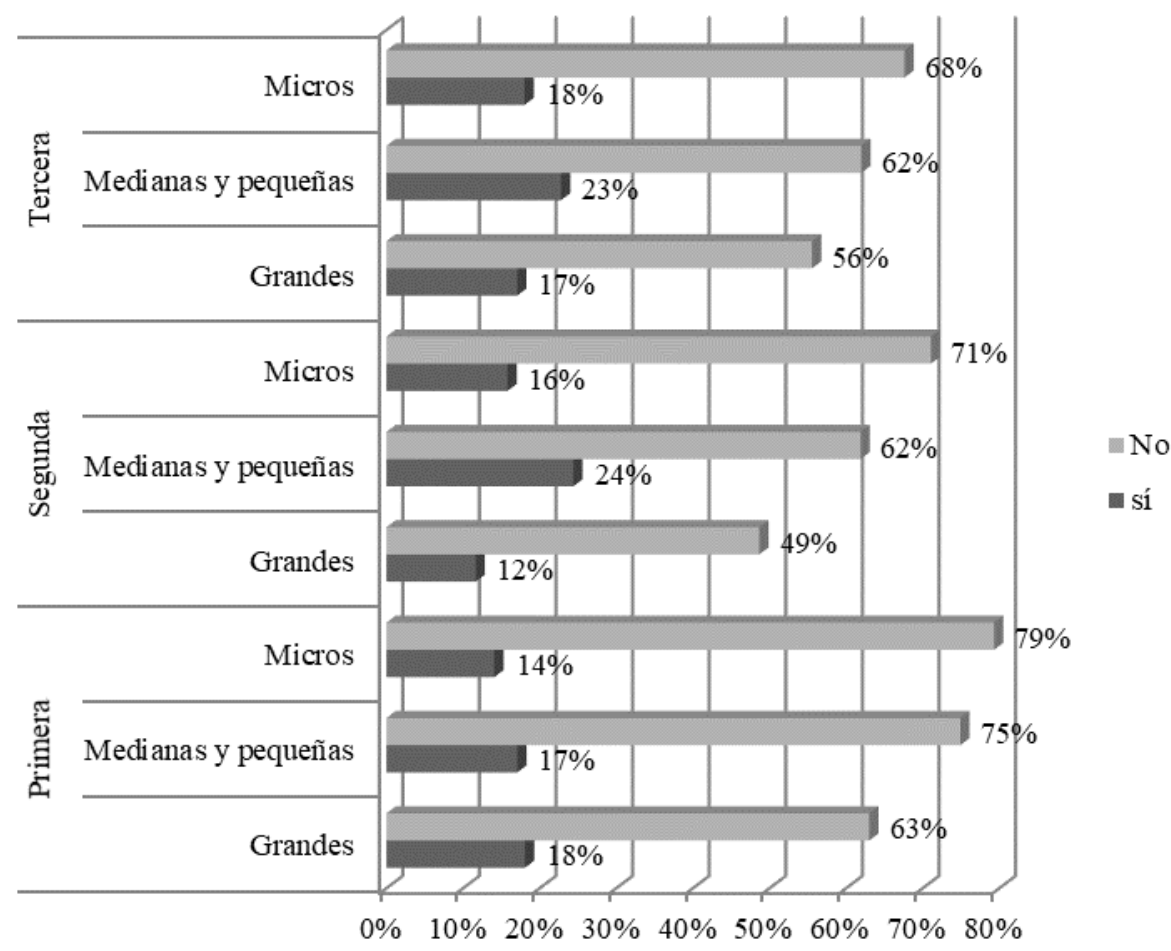

Fuente: Elaboración propia con datos emitidos en la ECOVID-IE 2021.

Gráfica 5.Porcentaje de empresas que redujeron remuneraciones y/o prestaciones al personal.

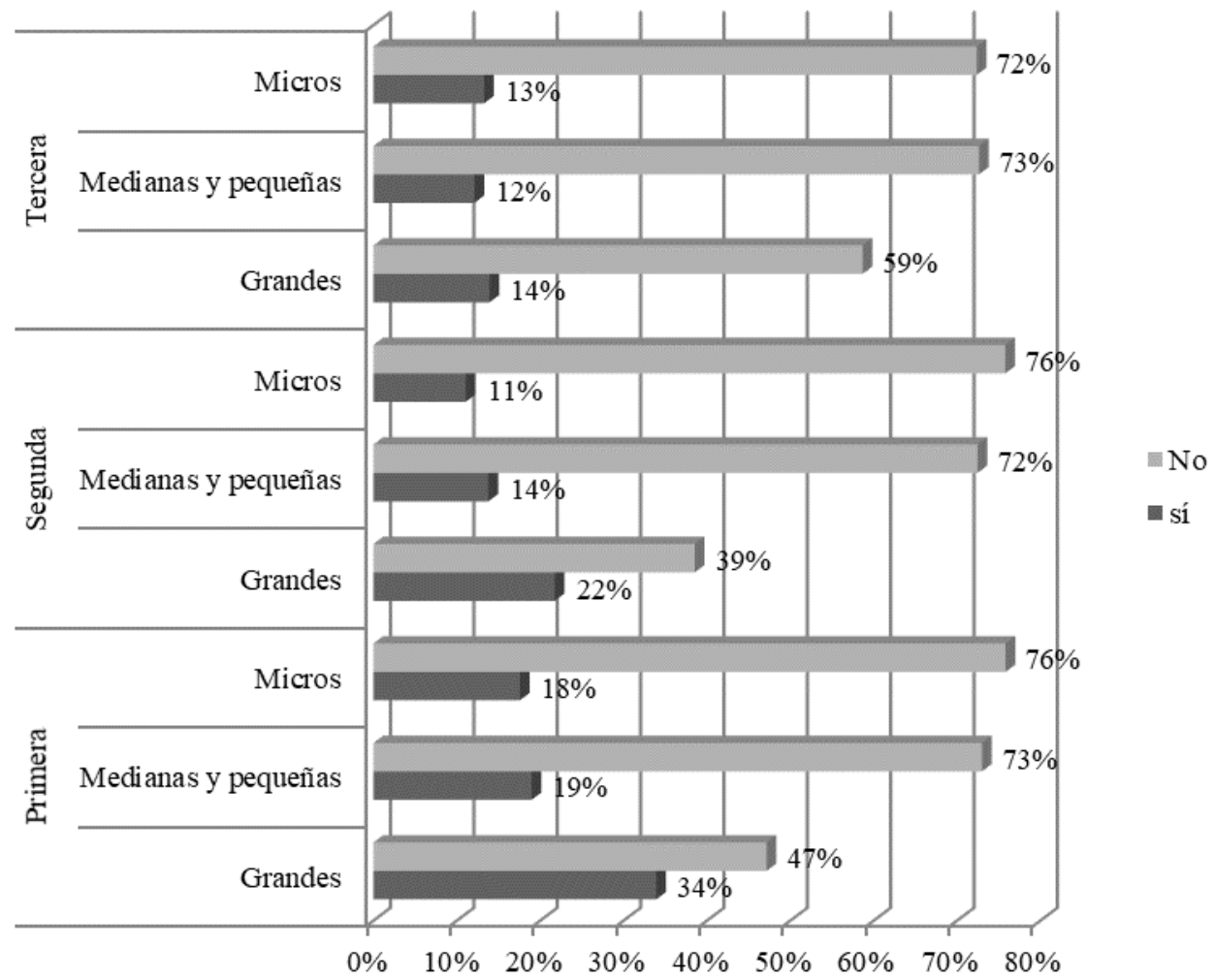

Fuente: Elaboración propia con datos emitidos en la ECOVID-IE 2021. 
En este mismo orden y dirección, el instrumento aplicado por el INEGI e intitulado en su acrónimo como ECOVID-ML, entre sus reactivos incluye una de las variables indispensables en correlación a las causas de la suspensión de labores, vinculándose y soportándose así los datos antes expuestos sobre las empresas con implementación de paros técnicos o cierres temporales ante la contingencia originada por Covid-19; ostentándose que en los meses de abril, mayo, junio y julio 2020, la principal causa de la interrupción laboral obedece a la pandemia, contexto por encima del 88\%; así como, la razón por la cual disminuyeron las horas de trabajo habituales; escenario que muestra un porcentaje igual o superior al $53 \%$ en tales períodos.

\section{Gráfica 6.Porcentaje de condición de ausencia temporal o suspensión laboral.}

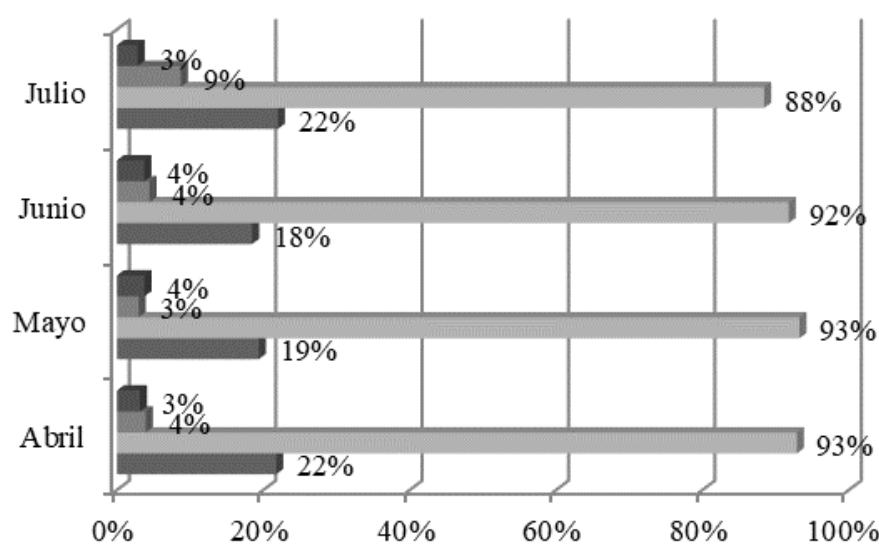

- Otra razón

- Razones de mercado

Por el COVID-19

- Ausentes temporales o con suspensión temporal

Fuente: Elaboración propia con datos emitidos en la ECOVID-ML 2020.

\section{Gráfica 7.Porcentaje sobre razones por las que no trabajo las horas habituales.}

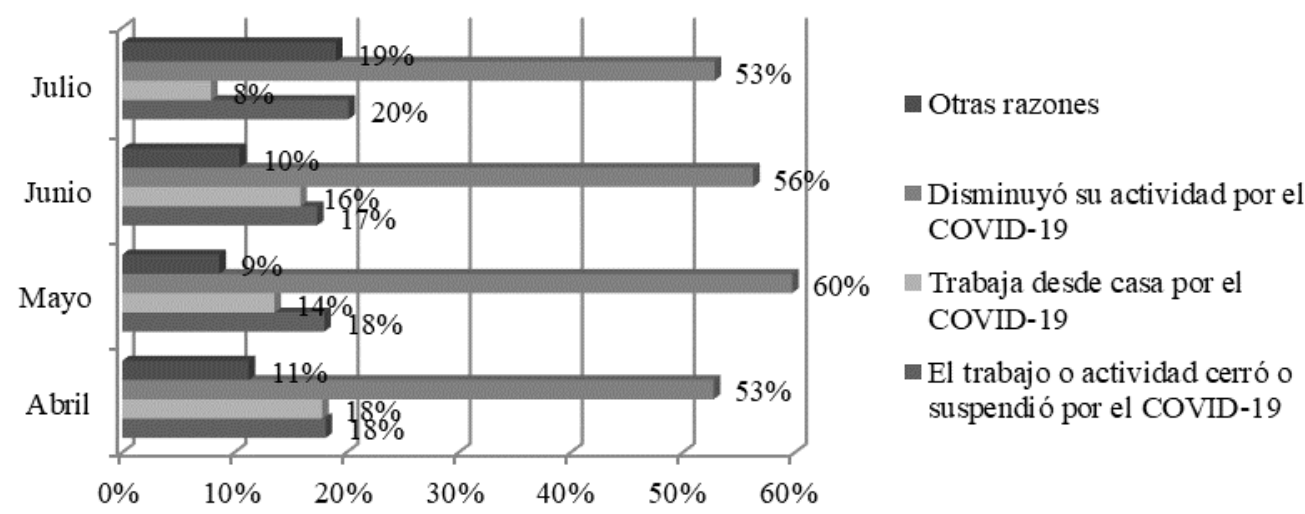

Fuente: Elaboración propia con datos emitidos en la ECOVID-ML 2020.

En esta misma tendencia, el IMSS muestra en sus datos abiertos el comportamiento y la gran afectación en los puestos de trabajo formales ante dicho instituto de seguridad social, ostentándose que al cierre del mes de febrero 2020 se contaba con más de 20.6 millones de trabajadores inscritos, período que reflejaba el mejor escenario en los últimos meses antes de la implementación de las actividades y medidas sanitarias. Una vez establecidas dichas medidas, al cierre del mes de julio se expone una disminución de más de 1.1 millón de empleos formales, cifra que representó más del $5 \%$ en correlación al mes de febrero y que reflejó el perjuicio laboral ocasionado por el Covid-19. 
De igual manera, en tales cifras se puede apreciar un incremento sustancial de los puestos de trabajo al mes de noviembre 2020, la reflejarse una diferencia positiva de 555,600 trabajadores colocados en la formalidad, lo que simbolizó cerca del 3\% de aumento. Sin embargo, al cierre del mes de diciembre del mismo año se ostenta una desafortunada disminución de 277,820 de trabajadores inscritos, representando una disminución del $1.4 \%$ en correlación al mes de noviembre. Pero además, a pesar de la recuperación de los puestos de trabajo formales después del confinamiento en el país, al cierre del mes de abril del 2021 se refleja una diferencia de 543,053 puestos de trabajos en correspondencia al mes de febrero del 2020 y que representa el 2.64\% menos a dicho período, manifestándose así la afectación del Covid-19 que aun impera en México.

\section{Gráfica 8. Comportamiento de los puestos de trabajo formales.}

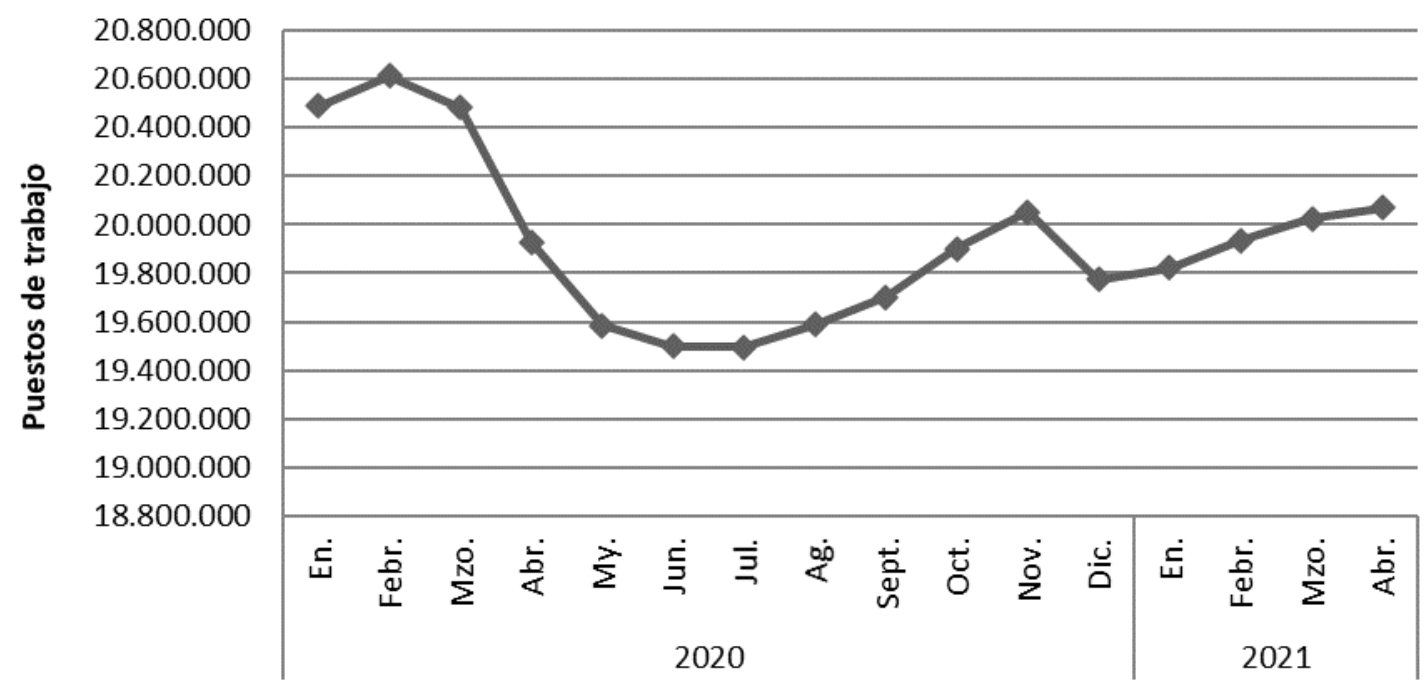

Fuente: Elaboración propia con datos emitidos por el IMSS.

\section{CONCLUSIÓN}

Evidentemente con la aparición del Covid-19 el gran desafío del 2020 y 2021 ha sido afrontar y superar una crisis sanitaria que ha conllevado en afectaciones a la salud y en la economía a nivel mundial, la cual ha demandado en varios países de acciones y medidas preventivas tales como el confinamiento, la cuarentena, el distanciamiento social y la suspensión de actividades económicas no esenciales.

Los distintos estudios han reflejado la crisis económica que se presentó durante y posterior al confinamiento a los distintos sectores en México, primordialmente al sector industrial, servicios de la construcción, servicios de hotelería y restaurantes; con afectaciones en la fuerza laboral del país, al mostrarse en el presente análisis la disminución de la Población Económicamente Activa por más de 10.2 millones, simbolizando cerca del 19\% de dicho rubro. Asimismo, se exhibe la ampliación de dicha población en situación de desocupada en un $15.36 \%$. Por si fuera poco, en lo datos vertidos por el IMSS, se refleja la gran incidencia en el empleo formal, al disminuirse los puestos de trabajo en poco más de un millón cien mil, contexto que aún en el mes de abril del 2021 no se supera en correlación al mes de febrero del 2020 que reveló la mayor cantidad de trabajadores inscritos en dicho instituto de seguridad social.

Asimismo, se puede apreciar en los datos expuestos a través de los instrumentos del INEGI, las afectaciones a la grande, micro, pequeña y mediana empresa en correlación a la suspensión técnica 
o cierre temporal, a la reducción de personal y disminución de las remuneraciones a los trabajadores, siendo el motivo principal de la interrupción laboral o disminución de las horas trabajadas el Covid-19; convergiendo así los resultados obtenidos con algunos de los estudios empíricos citados en el análisis.

Finalmente como es de advertirse, el estudio se limitó a los datos expuestos de los instrumentos de la ENOE, ECOVID-IE, ECOVID-ML, cifras manifestadas en sus tabulados predefinidos básicos, seleccionando en el proceso las variables que mostraran la incidencia del Covid-19 en el empleo en México, sin recurrir a un análisis minucioso a través de los microdatos disponibles en cada una de las herramientas aplicadas y emitidas por el INEGI mencionadas, así como en el apoyo de los datos abiertos emitidos por el IMSS al elegir solamente una de sus variables disponibles. Por lo tanto, sirvan las presentes observaciones para posteriores reflexiones teóricas, comparativas o experimentales en correspondencia a la incidencia de la pandemia en el empleo en México, antes, durante o posterior al escenario adverso que aún impera en México. De igual manera, queda pendiente en la agenda efectuar análisis en el ámbito del mercado laboral desde un enfoque doméstico regional, internacional, por sectores económicos y desde la perspectiva de género en correlación a las afectaciones ocasionadas por el Covid-19.

\section{REFERENCIAS}

Acevedo, I. et al. (2021). Informalidad en los tiempos del COVID-19 en América Latina: implicaciones y opciones de amortiguamiento. Banco Interamericano de Desarrollo. [En línea]. Disponible en:

https://publications.iadb.org/publications/spanish/document/Informalidad-en-los-tiempos-del-COVID-19-enAmerica-Latina-Implicaciones-y-opciones-de-amortiguamiento.pdf [Extraído el 24 de julio 2021]

CEPAL (2020). América Latina y el Caribe ante la pandemia del COVID-19. Efectos económicos y Sociales. Informe especial COVID-19 n. ${ }^{\circ}$. [En línea]. Disponible en:

https://repositorio.cepal.org/bitstream/handle/11362/45337/S2000264_es.pdf?sequence=6\&isAllowed=y [Extraído el 25 de julio 2021].

Cota, J. (2020). COVID-19 y el empleo en México: impacto inicial y pronósticos de corto plazo. Contaduría y Administración, 65 (4), Especial COVID-19, pp. 1-18. http://dx.doi.org/10.22201/fca.24488410e.2020.3028 [Extraído el 20 de julio 2021].

Covid-19 Tablero México. Covid-19 México. https://coronavirus.gob.mx/datos/ [Consultado el 29 de julio 2021].

DOF (2020). Acuerdo por el que se declara como emergencia sanitaria por causa de fuerza mayor, a la epidemia de enfermedad generada por el virus sars-CoV2 (covid-19).

http://www.dof.gob.mx/nota_detalle.php?codigo=5590745\&fecha=30/03/2020 [Consultado el 25 de julio del 2021].

DOF (2020). Acuerdo por el que se establecen acciones extraordinarias para atender la emergencia sanitaria generada por el virus sars-CoV2. http://www.dof.gob.mx/nota_detalle.php?codigo=5590914\&fecha=31/03/2020 [Consultado el 25 de julio del 2021].

DOF (2020). ACUERDO por el que se establecen las medidas preventivas que se deberán implementar para la mitigación y control de los riesgos para la salud que implica la enfermedad por el virus SARS-CoV2 (COVID19). [En línea]. Disponible en: https://www.dof.gob.mx/nota_detalle.php?codigo $=5590339 \&$ fecha $=24 / 03 / 2020$ [Consultado el 25 de julio del 2021].

DOF (2020). Acuerdo por el que se modifica el similar por el que se establecen acciones extraordinarias para atender la emergencia sanitaria generada por el virus sars-CoV2, publicado el 31 de marzo de 2020. http://www.dof.gob.mx/nota_detalle.php?codigo=5592067\&fecha=21/04/2020 [Consultado el 25 de julio del 2021].

DOF (2020). Decreto por el que se declaran acciones extraordinarias en las regiones afectadas de todo el territorio nacional en materia de salubridad general para combatir la enfermedad grave de atención prioritaria generada 
por el virus sars-CoV2 (covid-19).

https://www.dof.gob.mx/nota_detalle.php?codigo=5590673\&fecha=27/03/2020 [Consultado el 25 de julio del 2021].

ECOVID-ML (2020). Encuesta Telefónica sobre COVID-19 y Mercado Laboral. [En línea]. Disponible en: https://www.inegi.org.mx/investigacion/ecovidml/2020/ [Extraído el 20 de julio 2021].

ECOVID-IE (2021). Encuesta sobre el Impacto Económico Generado por COVID-19 en las Empresas. [En línea]. Disponible en: https://www.inegi.org.mx/programas/ecovidie/\#Tabulados [Extraído el 25 de julio del 2021]

ENOE (2021). Encuesta Nacional de Ocupación y Empleo, población de 15 años y más de edad. [En línea]. Disponible en: https://www.inegi.org.mx/programas/enoe/15ymas/\#Tabulados [Extraído el 25 de julio del 2021].

Huesca, L. \& Llamas, L (2020). MEXMOD Reporte País: MEXMOD v1.1, 2014-2020. El Centro de Investigación en Alimentación y Desarrollo, A.C. (CIAD).

Huesca, L., et al. (2021a). El impacto distributivo de la pandemia COVID-19 en México. El Centro de Investigación en Alimentación y Desarrollo, A.C. (CIAD), enero 2021. El impacto distributivo de la pandemia COVID-19 en México. El Centro de Investigación en Alimentación y Desarrollo, A.C [Extraído el 20 de julio 2021].

Huesca, L., et al. (2021b). The impact of the COVID-19 pandemic on poverty and inequality in Mexico. Revista Mexicana de Economía y Finanzas, Nueva Época, Volumen 16 Número 3, Julio - Septiembre, pp. 1-19, e633. DOI: https://doi.org/10.21919/remef.v16i3.633 [Extraído el 20 de julio 2021].

Huesca, L., et al. (2020). Efecto del COVID-19 en el empleo digital en México: un análisis con cadenas de Markov. PANORAMA ECONÓMICO, vol. XVI, núm. 32, julio-diciembre, pp. 151-168. http://www.panoramaeconomico.mx/ojs/index.php/PE/article/view/13 [Extraído el 20 de julio 2021].

IMSS. Datos abiertos IMSS. [En línea]. Disponible en: http://datos.imss.gob.mx/ [Extraído el 20 de julio del 2021].

IMSS. Mapa en tiempo real de casos de coronavirus por Johns Hopkins School.

http://cvoed.imss.gob.mx/mapa_coronavirus/ [Consultado el 29 de julio2021].

INEGI (2020a). Cómo se hace la ENOE: métodos y procedimientos. Instituto Nacional de Estadística y Geografía. 2 da. Edición. [En línea]. Disponible en:

https://www.inegi.org.mx/contenidos/productos/prod_serv/contenidos/espanol/bvinegi/productos/nueva_estruc 1702825190613.pdf [Extraído el 29 de julio del 2021].

INEGI (2020b). Encuesta Telefónica sobre COVID19 y Mercado Laboral 2020 ECOVID-ML. Instituto Nacional de Estadística y Geografía. 2da. Edición. [En línea]. Disponible en:

https://www.inegi.org.mx/contenidos/investigacion/ecovidml/2020/doc/ecovid_ml_diseno_conceptual.pdf [Extraído el 29 de julio del 2021].

INEGI (2020c). Encuesta sobre el Impacto Económico Generado por COVID-19 en las Empresas 2020 ECOVID-IE. Síntesis metodológica. Instituto Nacional de Estadística y Geografía. [En línea]. Disponible en: https://www.inegi.org.mx/contenidos/productos/prod_serv/contenidos/espanol/bvinegi/productos/nueva_estruc 1702825007028.pdf [Extraído el 29 de julio 2021].

Libertad y Desarrollo (2020). Coronavirus y sus Consecuencias Económicas. Temas Públicos, No. 1438-1. [En línea]. Disponible en: https://lyd.org/wp-content/uploads/2020/03/tp-1438-economia-y-covid.pdf [Extraído el 24 de julio 2021].

OIT (2021). Observatorio de la OIT: La COVID-19 y el mundo del trabajo. Séptima edición. Estimaciones actualizadas y análisis. [En línea]. Disponible en: https://www.ilo.org/wcmsp5/groups/public/---dgreports/--dcomm/documents/briefingnote/wcms_767045.pdf [Extraído el 26 de julio 2021].

Osorio, J. (2021). Covid-19 y la suspensión de la relación laboral por contingencia sanitaria en México. Con-texto. Revista de derecho y economía No. 55 enero-junio, pp. 167-176. https://doi.org/10.18601/01236458.n55.14 [Extraído el 20 de julio 2021].

Ramírez, et al. (2020). COVID-19: historia actual de una pandemia y sus hallazgos clínico-radiológicos. Anales de Radiología México, Volumen 19, No. 2, pp. 1-11. [En línea]. Disponible en: https://www.analesderadiologiamexico.com/frame_esp.php?id=102 [Extraído el 24 de julio del 2021]. 
Rodríguez, C. (2013). Diccionario de economía: etimológico, conceptual y procedimental: edición especial para estudiantes. [En línea]. Disponible en: https://repositorio.uca.edu.ar/bitstream/123456789/5559/1/diccionarioeconomia-etimologico-conceptual.pdf [Extraído el 29 de julio 2021].

Salas, C., et al. (2020). Distribución del ingreso laboral y la pobreza en México durante la pandemia de la Covid-19. Escenarios e impactos potenciales. EL TRIMESTRE ECONÓMICO, vol. LXXXVII (4), núm. 348, octubrediciembre, pp. 929-962 doi: 10.20430/ete.v87i348.1148

Samaniego, N. (2020). El Covid-19 y el desplome del empleo en México. Economíaunam vol. 17, núm. 51, septiembrediciembre, pp. 306-314. https://doi.org/10.22201/fe.24488143e.2020.51.566 [Extraído el 20 de julio 2021].

Secretaria de Salud. 076. COVID-19: Acciones de preparación y respuesta en México. Disponible en: https://www.gob.mx/salud/prensa/076-covid-19-acciones-de-preparacion-y-respuesta-en-mexico [Consultado el 25 de julio del 2021]. 